\title{
Inspeção Predial em Edifício Histórico - Estudo de Caso da Capela de Leitão da Cunha no Município Trajano de Moraes - RJ
}

\author{
A. C. G. Lessa ${ }^{1}$, R. G. Faisca ${ }^{*}$, P. F. P. C. Fazzioni ${ }^{3}$, C. S. T. Carmo ${ }^{4}$, N. A. Bernardino ${ }^{5}$ \\ *renatafaisca@id.uff.br \\ ${ }^{1}$ Graduanda do Curso Engenharia Civil, Universidade Federal Fluminense, Niterói, RJ, Brasil \\ ${ }^{2}$ Docente do Departamento de Engenharia Civil, Universidade Federal Fluminense, Niterói, RJ, Brasil \\ ${ }^{3}$ Doutor em Engenharia Civil, Empresa TSR, Niterói, RJ, Brasil \\ ${ }^{4}$ Doutorando em Engenharia Civil, Pontificia Universidade Católica, Rio de Janeiro, RJ, Brasil \\ ${ }^{5}$ Mestrando do Curso de Engenharia de Biossistemas, Universidade Federal Fluminense, Niterói, RJ, Brasil
}

\begin{abstract}
RESUMO
O artigo fundamenta-se na área de Engenharia Diagnóstica. Objetiva-se a Inspeção Predial, a classificação dos níveis de criticidade das manifestações patológicas, empregando-se a metodologia GUT (Gravidade, Urgência e Tendência), e a determinação das possíveis soluções construtivas às fachadas e cobertura da Capela de Leitão da Cunha, localizada em Trajano de Moraes, Estado do Rio de Janeiro, Brasil. Ademais. Foi feita uma pesquisa bibliográfica em artigos científicos, livros técnicos e normas da Associação Brasileira de Normas Técnicas, destacando-se a ABNT NBR 16747:2020, recentemente publicada. A inspeção limitou-se às fachadas do edifício e sua cobertura devido à inacessibilidade ao seu interior. Por ser uma edificação antiga, concluiuse que seu estado não está em deterioração avançada, o que facilita um plano de manutenção predial adequado.
\end{abstract}

Palavras-chave: Inspeção Predial; Edifícios Históricos; Engenharia Diagnóstica; Manifestações Patológicas. 


\begin{abstract}
The article is based on the area of Diagnostic Engineering. The objective of the Building Inspection is to classify the criticality levels of pathological manifestations, applying the GUT (Gravity, Urgency and Trend) method, and determine the possible constructive solutions to the facades and coverage of the Leitão da Cunha Chapel, located in Trajano de Moraes city, State of Rio de Janeiro, Brazil. In addition, a bibliographic search was carried out on scientific articles, technical books, and technical standards of the Brazilian Association of Technical Standards, highlighting the recently published ABNT NBR 16747: 2020. The inspection was limited to the building's façades and their coverage due to the inaccessibility to the interior area. As it is an old building, it was concluded that its condition is not in advanced deterioration, which facilitates an adequate building maintenance plan.
\end{abstract}

Keywords: Building Inspection; Historic Buildings; Diagnostic Engineering; Pathological Manifestations.

\title{
RESUMEN
}

El artículo está basado en el área de Ingeniería Diagnóstica. El objetivo de la Inspección de Edificación es clasificar los niveles de criticidad de las manifestaciones patológicas, aplicando la metodología GUT (Gravedad, Urgencia y Tendencia), y determinar las posibles soluciones constructivas a las fachadas y cobertura de la Capilla Leitão da Cunha, ubicada en Trajano de Moraes, Estado de Rio de Janeiro, Brasil. Además, se realizó una búsqueda bibliográfica de artículos científicos, libros técnicos y normas técnicas de la Asociación Brasileña de Normas Técnicas, destacando la recientemente publicada ABNT NBR 16747: 2020. La inspección se limitó a las fachadas del edificio y su cobertura debido a la inaccesibilidad a su interior. Al tratarse de un edificio antiguo, se concluyó que su estado no se encuentra en deterioro avanzado, lo que facilita un adecuado plan de mantenimiento del edificio.

Palabras clave: Inspección de Edificios; Edificios históricos; Ingeniería de diagnóstico; Manifestaciones patológicas.

\section{INTRODUÇÃO}

Na Engenharia Civil, a importância da excelência na concepção, no cálculo e na construção de uma edificação são partes integrantes de um projeto. Além disso, uma etapa essencial é a manutenção da edificação. O presente trabalho aborda as manifestações patológicas existentes em uma edificação no Estado do Rio de Janeiro, Brasil. No âmbito deste estado, foi sancionada a Lei Estadual $n^{0}$ 6400, em 05 de março de 2013, tornando obrigatória a realização de Autovistoria em edifícios comerciais, residenciais e prédios públicos. Porém, a referida lei não institui obrigatoriedade em edifícios históricos que não são tombados. A inexistência, nesse caso, da inspeção predial e, consequentemente, de adequada manutenção faz com que esses edifícios, cada vez mais se deteriorem e percam a sua história, tanto da própria construção, como também do contexto cultural ao longo dos anos. Logo, torna-se fundamental o conhecimento e a determinação dos agentes causadores das manifestações patológicas para determinar a manutenção adequada a fim de que a edificação seja preservada. 


\subsection{Inspeção Predial}

A inspeção predial é um serviço que se insere na disciplina de Engenharia Diagnóstica, que compreende a investigação técnica a fim de melhorar a qualidade da edificação. Segundo (Gomide et. al., 2015), a inspeção predial é definida como sendo "a análise técnica de fato, condição ou direito relativo a uma edificação, com base em informações genéricas e na experiência do engenheiro diagnóstico." A inspeção predial atesta o estado do imóvel e lista as manifestações patológicas existentes, o que faz com que essa possua diversos objetivos como, por exemplo, auxiliar o plano de manutenção predial.

A primeira norma técnica sobre Inspeção Predial no Brasil foi desenvolvida pelo Instituto Brasileiro de Avaliações e Perícias (IBAPE) de São Paulo. Sua primeira publicação foi em 2001, alcançando a nível nacional no ano de 2012 (IBAPE, 2012). Durante algum tempo, foi a única norma que apresentava critérios para a realização do serviço de inspeção predial, já que antes de sua primeira publicação inexistia uma norma específica para tal serviço. Seu objetivo também apresenta a determinação dos procedimentos e conceitos referentes ao assunto.

A NBR 16747:2020 é a norma atual da Associação Brasileira de Normas Técnicas, ABNT, que aborda o assunto de inspeções predial e define suas diretrizes e procedimentos, entrou em vigor em maio de 2020. A NBR 16747:2020 pode ser aplicada aos edifícios com diferentes tipologias, públicas ou privadas. Essa norma estabelece conceitos, diretrizes, terminologia e procedimentos relativos à inspeção predial, uniformizando a metodologia a ser empregada e definindo as suas etapas mínimas necessárias ao serviço. A inspeção predial, conforme definição da NBR 16747:2020, consiste em uma avaliação global da edificação, observando-se o estado de conservação e a conformidade da sua manutenção com a ABNT NBR 5674:2012, a qual estabelece os requisitos para a gestão do sistema de manutenção de edificações. Segundo a NBR 5674:2012, o sistema de gestão de manutenção deve incluir meios para preservar as características originais da edificação e prevenir a perda de desempenho decorrente da degradação dos seus sistemas, elementos ou componentes.

\subsection{Manifestações Patológicas em Edifícios Históricos}

As construções possuem um valor cultural muito alto, pois a partir destas é registrada a evolução da humanidade e das sociedades. Conhecer o modo como estas foram construídas e os materiais que as compõem é fundamental para uma atuação precisa na preservação ao longo do tempo (Franco et. al., 2020). Segundo (Teixeira e Silva, 2020), o estudo de causas e efeitos das manifestações patológicas são imprescindíveis na concepção de estratégias de intervenções para a preservação do patrimônio. Já um estudo sobre as manifestações patológicas é de essencial importância, quando se pretende adquirir qualidade nas intervenções realizadas nas obras do patrimônio e, também, colaboram para prevenção dos danos (Temp. et al., 2020).

As manifestações patológicas podem ser classificadas em anomalias ou falhas e de acordo com o seu grau de risco. As anomalias envolvem perda de desempenho do tipo funcional ou construtiva, enquanto as falhas são tipificadas pela perda de desempenho relacionadas ao uso, operação e manutenção. As anomalias ainda podem ser divididas em endógena ou construtiva, caso sua origem for devido ao projeto ou à execução; exógena quando sua origem for devido à fatores externos e funcional, quando acontece devido ao envelhecimento natural.

De acordo com o Instituto Brasileiro de Avaliações e Perícias (IBAPE, 2012), as falhas podem ser classificadas como de planejamento, de execução, operacionais ou gerenciais. As falhas de planejamento ocorrem devido à inexistência de um plano de manutenção ou à sua inadequação. Enquanto as falhas de execução, referem-se às falhas que decorrem da inadequada execução do plano de manutenção. 
Segundo a NBR 16747:2020 da ABNT, as manifestações patológicas podem ser categorizadas como graus de urgência, sendo prioridade 1 quando ocorre o comprometimento do desempenho, segurança dos usuários, ou seja, quando pode gerar graves riscos, tanto para a edificação quanto para as pessoas e meio ambiente. A prioridade 2 quando ocorre o comprometimento parcial do desempenho, mas que não gere sérios riscos aos usuários. Já a prioridade 3, está no nível mais baixo, visto que na maioria das vezes envolvem questões estéticas que não causam nenhum risco grave e que não necessitem de ações urgentes. Assim, é possível elaborar uma lista de prioridades, onde as manifestações patológicas são organizadas, de acordo com a classificação do grau de risco e intensidade, pela ordem da mais crítica para a mínima.

(Prieto et. al., 2017) propõem que as ações para reforma e restauração devem ser avaliadas após identificação e análise das patologias mais relevantes que influenciam diretamente na perda de funcionalidade e desempenho da edificação, para isso foram estudados edifícios históricos de igrejas paroquiais em Sevilha, Espanha, onde as manifestações patológicas foram associadas com a obsolescência funcional dos edifícios.

\section{MATERIAIS E MÉTODOS}

Nesse trabalho, é aplicada a metodologia da obtenção da lista de prioridades através da matriz GUT, uma ferramenta que auxilia na priorização de resolução de problemas, nesse caso, consiste em pontuar a manifestação patológica constatada de acordo com a gravidade, urgência e tendência, onde cada aspecto possui um peso e o peso final da manifestação patológica é obtido multiplicandose todos os pesos. A ordem de prioridade é então formada em sequência decrescente, onde a manifestação patológica com maior peso é considerada um grau de criticidade maior. (Araújo, 2018) utilizou a Matriz de GUT para auxiliar o restauro de três igrejas históricas dos séculos XVII e XVIII no Estado do Rio Grande do Norte. Com a metodologia, foi possível identificar os danos mais relevantes de cada edificação. (Braga et. al., 2019) aplicou a metodologia da Matriz GUT na análise das manifestações patológicas em edificações históricas em Sobral, Ceará, Brasil, mostrando que é uma importante ferramenta de gestão da manutenção de edificações. Neste trabalho, utilizou-se a sugestão de classificação segundo a matriz GUT, proposta por (Gomide et. al., 2019), conforme a Tabela 1 .

Tabela 1. Classificação dos níveis de criticidade segundo a metodologia GUT.

\begin{tabular}{|c|c|l|c|c|}
\hline Grau & Nota & \multicolumn{1}{|c|}{ Gravidade } & Urgência & Tendência \\
\hline Máximo & 10 & $\begin{array}{l}\text { Risco à vida dos usuários, colapso da edificação, } \\
\text { dano ambiental grave }\end{array}$ & $\begin{array}{c}\text { Evolução } \\
\text { imediata }\end{array}$ & $\begin{array}{c}\text { Em } \\
\text { ocorrência }\end{array}$ \\
\hline Alto & 8 & $\begin{array}{l}\text { Risco de ferimentos aos usuários, avaria não } \\
\text { recuperável na edificação, contaminação } \\
\text { localizada }\end{array}$ & $\begin{array}{l}\text { Evolução a } \\
\text { curto prazo }\end{array}$ & ocorrer \\
\hline Médio & 6 & $\begin{array}{l}\text { Insalubridade aos usuários, deterioração elevada da } \\
\text { edificação, desperdício dos recursos naturais }\end{array}$ & $\begin{array}{c}\text { Evolução a } \\
\text { médio prazo }\end{array}$ & $\begin{array}{c}\text { Prognóstico } \\
\text { para breve }\end{array}$ \\
\hline Baixo & 3 & $\begin{array}{l}\text { Incômodo aos usuários, degradação da edificação, } \\
\text { uso não racional dos recursos naturais }\end{array}$ & $\begin{array}{c}\text { Evolução a } \\
\text { longo prazo }\end{array}$ & $\begin{array}{c}\text { Prognóstico } \\
\text { para adiante }\end{array}$ \\
\hline Mínimo & 1 & Depreciação imobiliária & Não evoluirá & Imprevisto \\
\hline
\end{tabular}

Fonte: (Gomide et. al., 2019). 


\section{ESTUDO DE CASO}

A edificação estudada é a Capela de Leitão da Cunha, uma edificação histórica existente no interior do estado do Rio de Janeiro. A Capela situa-se na localidade Leitão da Cunha no município de Trajano de Moraes, que está situado na região serrana do norte fluminense, onde há fazendas históricas oriundas do período imperial. Para maiores detalhes sobre a edificação em estudo, consultar (Lessa, 2021).

A capela encontra-se em uma propriedade particular, sendo posteriormente doada à Mitra. Após pesquisas, foi apurado que como consiste em uma edificação doada, não é possível precisar a data de sua construção. Entretanto, é possível que date do século XIX, devido ao seu estilo arquitetônico, muito característico das capelas encontradas no interior do Brasil. Vale ressaltar que não há registros de tombamento histórico da edificação.

Com o intuito de estudar a edificação, foi realizada uma visita preliminar na Capela, onde foi possível obter informações importantes. Foi constatada que a estrutura da edificação possivelmente é composta por tijolos maciços. Adicionalmente, foi apurado que a edificação passa por uma reforma interna, tornando-se impossível o acesso ao seu interior, visto que se encontrava fechada à visitação. Por esse motivo, a limitação do estudo é a verificação das manifestações patológicas existentes nas fachadas externas e na cobertura da edificação.

Constatou-se, que a edificação em questão, não possui manifestações patológicas críticas e/ou estruturais. A maioria das manifestações são oriundas do processo de degradação e envelhecimento natural da edificação, problemas de umidade e falhas decorrentes da inadequada ou falta de manutenção.

As manifestações patológicas encontradas, na fachada frontal e fachada sul, são vegetação na escadaria, vegetação na cobertura, falta de telhas no beiral, descolamento de parte do revestimento argamassado e manchas escuras na parede, como mostra a Figura 1.

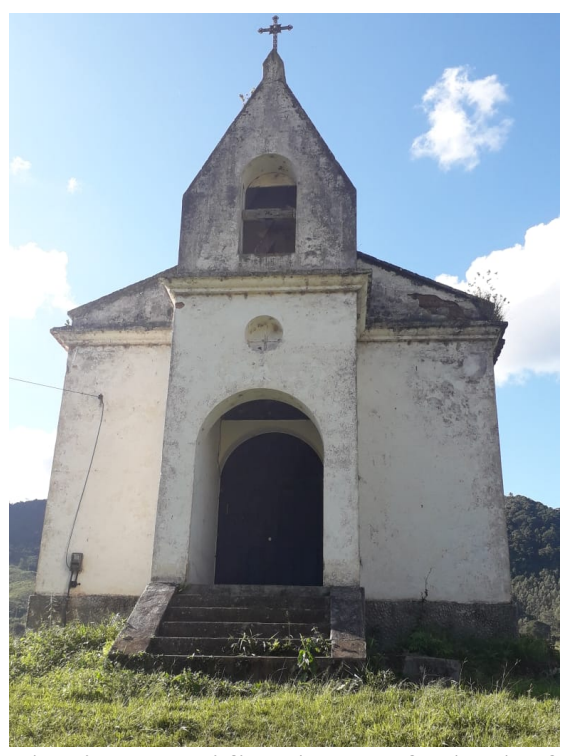

Figura 1. Manifestações patológicas verificadas na fachada frontal. Fonte: (Lessa, 2021).

$\mathrm{Na}$ fachada Leste, foram verificados os seguintes problemas: manchas escuras no revestimento, falta de telhas no beiral, esquadrias danificadas e descolamento do revestimento argamassado, como apresenta a Figura 2. 


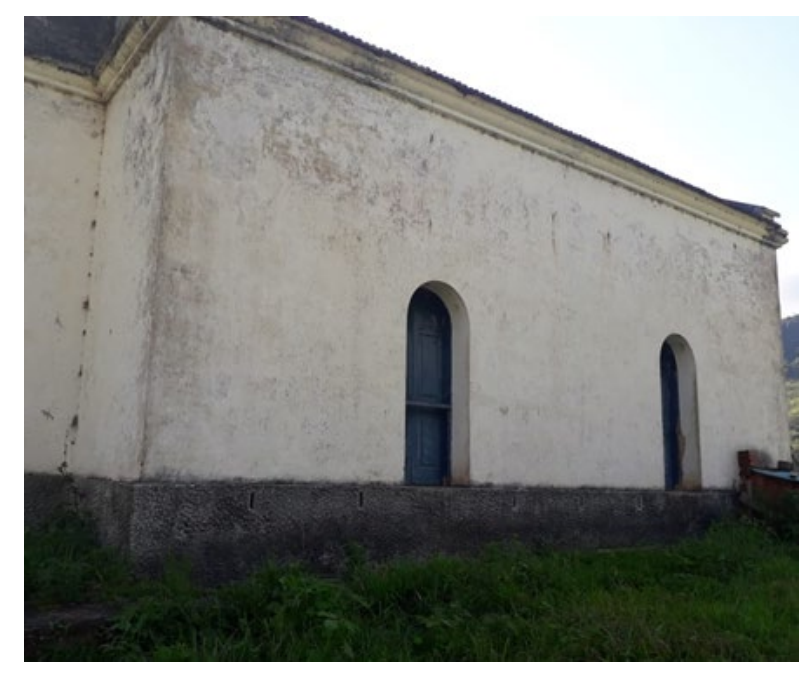

Figura 2. Manifestações patológicas verificadas na fachada leste. Fonte: (Lessa, 2021).

$\mathrm{Na}$ fachada oeste foram verificadas as seguintes patologias: umidade ascendente, manchas escuras no revestimento, fissuras, falta de telhas no beiral, esquadrias danificadas e descolamento do revestimento argamassado, como mostra a Figura 3.

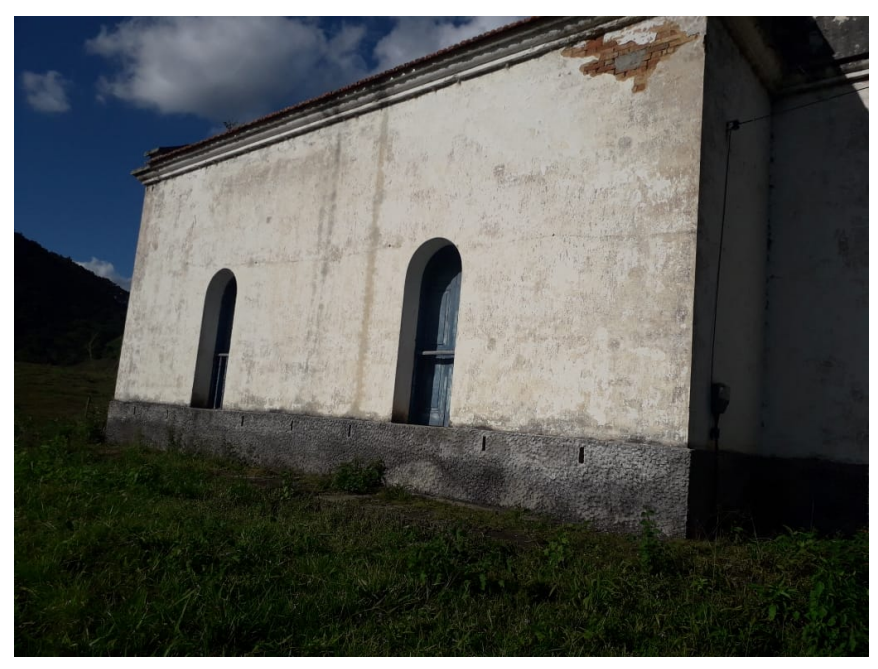

Figura 3. Manifestações patológicas verificadas na fachada oeste. Fonte: (Lessa, 2021).

Já na fachada Norte, foram encontrados vegetação nas paredes, acúmulo de entulhos de obra, partes com descolamento do revestimento argamassado, falta de telhas no beiral e machas escuras no revestimento, como apresenta a Figura 4. 


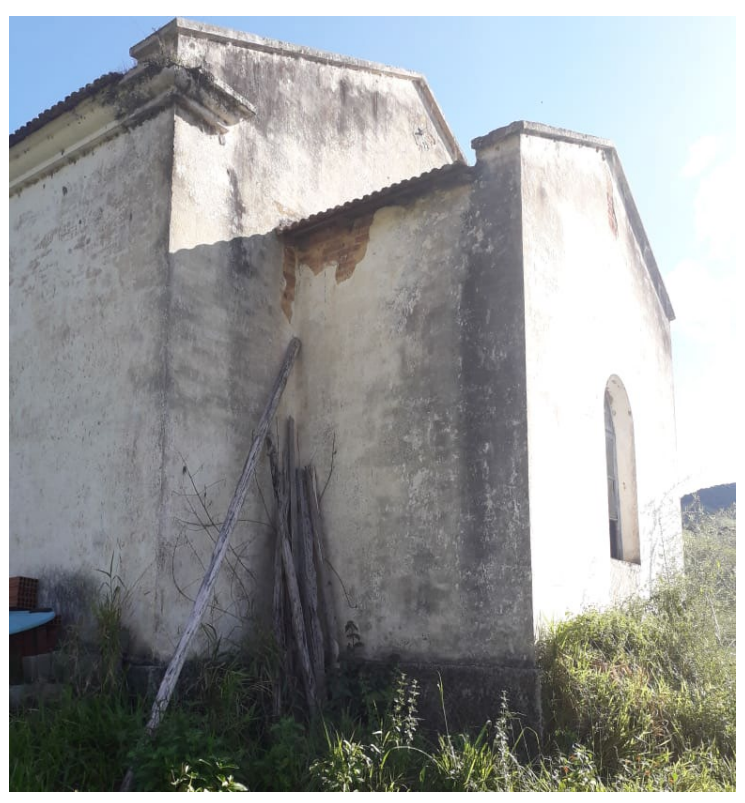

Figura 4. Manifestações patológicas verificadas na fachada norte. Fonte: (Lessa, 2021).

\section{RESULTADOS}

A Tabela 2 apresenta as informações sobre as manifestações patológicas encontradas nas fachadas da Capela, de acordo com o tipo, e apresenta a classificação dos níveis de criticidade, segundo a metodologia GUT. Com isso, é possível definir uma lista de prioridades das manifestações patológicas, como sendo a falta de telhas no beiral e os descolamentos dos revestimentos argamassados, as quais são indicadas como as patologias prioritárias a serem reparadas. A partir dessas informações, é possível definir as possíveis causas das manifestações patológicas e propor soluções, as quais são apresentadas no Quadro 1. As patologias também foram classificadas segundo o grau de urgência estabelecido pela norma NBR 16747:2020.

Tabela 2. Classificação dos níveis de criticidade segundo a metodologia GUT.

\begin{tabular}{|c|c|c|c|c|}
\hline Manifestação Patológica & Gravidade & Urgência & Tendência & Total \\
\hline $\begin{array}{c}\text { Descolamento do } \\
\text { revestimento argamassado }\end{array}$ & 6 & 6 & 10 & 360 \\
\hline Falta de telhas no beiral & 6 & 6 & 10 & 360 \\
\hline Vegetação na cobertura & 3 & 6 & 10 & 180 \\
\hline Vegetação na escadaria & 3 & 6 & 10 & 180 \\
\hline Manchas escuras na parede & 3 & 6 & 10 & 180 \\
\hline Fissuras & 3 & 3 & 10 & 90 \\
\hline Esquadrias danificadas & 3 & 3 & 10 & 90 \\
\hline $\begin{array}{c}\text { Acúmulo de entulho de } \\
\text { obra }\end{array}$ & 3 & 1 & 10 & 30 \\
\hline
\end{tabular}

Quadro 1. Fatores causadores e soluções para as manifestações patológicas verificadas. 


\begin{tabular}{|c|c|c|c|c|}
\hline $\begin{array}{l}\text { Manifestação } \\
\text { Patológica }\end{array}$ & Classificação & Causa & Solução & $\begin{array}{c}\text { Grau de } \\
\text { urgência } \\
\text { segundo } \\
\text { NBR16747 } \\
\end{array}$ \\
\hline Fissuras & Anomalia & Intempéries & $\begin{array}{l}\text { Recomposição do } \\
\text { revestimento } \\
\text { danificado } \\
\end{array}$ & Prioridade 1 \\
\hline $\begin{array}{c}\text { Manchas escuras } \\
\text { na parede }\end{array}$ & Anomalia & $\begin{array}{c}\text { Falta de } \\
\text { impermeabilização }\end{array}$ & $\begin{array}{l}\text { Impermeabilização e } \\
\text { pintura das fachadas }\end{array}$ & Prioridade 1 \\
\hline $\begin{array}{l}\text { Descolamento do } \\
\text { revestimento } \\
\text { argamassado }\end{array}$ & Anomalia & $\begin{array}{c}\text { Falta de } \\
\text { impermeabilização }\end{array}$ & $\begin{array}{l}\text { Recomposição do } \\
\text { revestimento, } \\
\text { impermeabilização e } \\
\text { pintura das fachadas }\end{array}$ & Prioridade 2 \\
\hline $\begin{array}{l}\text { Vegetação na } \\
\text { cobertura }\end{array}$ & Falha & $\begin{array}{c}\text { Falta de manutenção } \\
\text { do telhado }\end{array}$ & Limpeza da cobertura & Prioridade 1 \\
\hline $\begin{array}{l}\text { Vegetação na } \\
\text { escadaria }\end{array}$ & Falha & $\begin{array}{c}\text { Falta de manutenção } \\
\text { e limpeza }\end{array}$ & $\begin{array}{c}\text { Limpeza e } \\
\text { impermeabilização da } \\
\text { escadaria }\end{array}$ & Prioridade 1 \\
\hline $\begin{array}{l}\text { Esquadrias } \\
\text { danificadas }\end{array}$ & Falha & $\begin{array}{c}\text { Envelhecimento } \\
\text { natural }\end{array}$ & $\begin{array}{c}\text { Troca das esquadrias } \\
\text { danificadas }\end{array}$ & Prioridade 1 \\
\hline $\begin{array}{l}\text { Acúmulo de } \\
\text { entulho de obra }\end{array}$ & Falha & $\begin{array}{c}\text { Falta de adequada } \\
\text { manutenção e } \\
\text { limpeza }\end{array}$ & Retirada do entulho & Prioridade 1 \\
\hline $\begin{array}{c}\text { Falta de telhas no } \\
\text { beiral }\end{array}$ & Falha & $\begin{array}{l}\text { Falta de manutenção } \\
\text { no beiral }\end{array}$ & $\begin{array}{l}\text { Revisão do telhado, } \\
\text { impermeabilização e } \\
\text { reforma do beiral }^{1}\end{array}$ & Prioridade 2 \\
\hline
\end{tabular}

Nota 1: É necessário um estudo para não interferir na arquitetura original da edificação.

Inicialmente foram verificadas as manifestações patológicas existentes na edificação estudada, com isso foi possível aplicar a metodologia GUT proposta por (Gomide et. al., 2019) com o objetivo de definir as patologias mais importantes presentes na construção, definindo seus níveis de criticidade conforme apresentado na Tabela 2. Como as manifestações patológicas estão organizadas por ordem de maior gravidade, consequentemente, obtém-se a lista de prioridades das manifestações. De posse da lista, é possível classificar as patologias em falhas e anomalias para posteriormente classificá-las segundo o grau de urgência proposto pela norma NBR 16747:2020, conforme o Quadro 1. Nesse quadro, verifica-se a predominância de problemas classificados como falhas, indicando a falta de manutenção na edificação. Analisando as manifestações patológicas e as respectivas causas, constata-se que os principais problemas ocorreram no sistema de cobertura. Portanto, como solução prioritária, destaca-se a revisão da cobertura, limpeza, troca de telhas e recomposição de alguns elementos do telhado, impermeabilização e pintura. Em seguida, os serviços de recomposição do revestimento, impermeabilização e pintura das fachadas. Cabe salientar que as fachadas ficaram bem danificadas devido aos problemas que ocorreram no sistema cobertura.

Foi possível constatar que a classificação das prioridades, a partir da norma NBR 16747:2020, corroboram com os dados verificados através da aplicação da metodologia GUT para a análise das 
patologias. Portanto, o emprego da norma NBR 16747:2020 em complemento a metodologia GUT, torna-se fundamental para a proposta de um plano de manutenção da edificação adequado.

\section{CONCLUSÃO}

$\mathrm{O}$ presente artigo atingiu seu objetivo, pois analisou questões referentes às manifestações patológicas, listou e classificou as encontradas na edificação histórica em estudo, a partir da revisão bibliográfica e da análise da edificação, confirmando-se a importância da inspeção predial para a segurança das edificações.

O diagnóstico das patologias de um edifício visa identificar e avaliar manifestações, caracterizando anomalias e falhas. Verificar e ser capaz de detectar os mecanismos de formação inicial das patologias. Estabelecer grau de prioridade, procedimentos e recomendações para o tratamento e prevenção. A partir de um diagnóstico, é possível planejar as atividades e decidir desde pequenos reparos e reformas, até recuperação e restauração da edificação. Todas as observações e informações coletadas buscam levantar o histórico das manifestações patológicas da edificação.

As patologias encontradas na Capela de Leitão da Cunha indicam os problemas que surgiram ao longo de sua existência, tornando-se importante a preservação de suas características históricas e culturais. Foi aplicada a metodologia GUT, por meio da classificação dos níveis de criticidade de acordo com as manifestações patológicas existentes na edificação histórica. A partir da lista de prioridades foi possível constatar que as falhas devido à falta de telhas no beiral e os descolamentos dos revestimentos argamassados são indicados como as patologias prioritárias a serem reparadas na Capela de Leitão da Cunha. $\mathrm{Na}$ análise da lista, constatou-se que a cobertura da edificação representa o pior caso encontrado no objeto de estudo, visto que as manifestações patológicas devido à falta de telhas no beiral e a vegetação na cobertura, somam ao todo criticidade de 540 pontos. Outro quesito importante que deve ser destacado é o fato de a situação da cobertura influenciar diretamente no descolamento do revestimento argamassado, que é a segunda principal patologia verificada. Essa influência foi fundamentada pelo fato de que tal descolamento se encontra na parte superior do edifício, sendo então descartada a umidade por ascensão capilar.

Foi possível validar que a metodologia GUT é adequada para avaliar as manifestações patológicas, inclusive corroborando com a recente norma NBR 16747:2020.

Destaca-se a importância da inspeção dos edifícios históricos, visto que percolam diversas gerações de um povo, contando toda a sua história e costumes. É muito importante, que cada vez mais, a inspeção e a manutenção predial sejam difundidas para que tais edifícios possam ter uma adequada manutenção, fazendo com que a história nunca se apague.

Como trabalho futuro, sugere-se que seja elaborado um manual para auxiliar com as medidas de conservação e manutenção dos prédios históricos, incluindo um programa de manutenção corretiva a fim de recuperar o desempenho perdido.

\section{AGRADECIMENTOS}

Agradecemos à Universidade Federal Fluminense pelo suporte financeiro.

\section{REFERÊNCIAS}


Araújo, A. T. O. (2018). "Estudo das alvenarias de edificações históricas - arquitetura religiosa do período colonial, no Rio Grande do Norte, com ênfase no sistema construtivo, manifestações patológicas e aplicação da matriz GUT’. 195f. Dissertação (Mestrado em Engenharia Civil) Centro de Tecnologia, Universidade Federal do Rio Grande do Norte, Natal, RN, Brasil.

Associação Brasileira de Normas Técnicas. (2020). "NBR 16747: Inspeção Predial - Diretrizes, conceitos, terminologia e procedimento”. Rio de Janeiro., RJ, Brasil.

Associação Brasileira de Normas Técnicas. (2012). "NBR 5674: Manutenção de edificações Requisitos para o sistema de gestão de manutenção”. Rio de Janeiro., RJ, Brasil.

Braga, I. C., Brandão, F. S., Ribeiro, F. R. C., Diógenes, A. G. (2019), “Aplicação da Matriz GUT na análise de manifestações patológicas em construções históricas”, Revista ALCONPAT, 9(3), pp. 320 - 335, DOI: http://dx.doi.org/10.21041/ra.v9i3.400.

Franco, A. C., Carmo, C. S.T. e Faisca, R. G. (2020). "Mapeamento de Manifestações Patológicas em Edifícios Utilizando HBIM" V Congresso Internacional na Recuperação, Manutenção e Restauração de Edifícios (CIRMARE), Rio de Janeiro., RJ, Brasil.

Gomide, T. L. F., Gullo, M. A., Neto, J. C. P. F, Flora, S. M. D. (2019), “Inspeção Predial Total”. Oficina de Textos, São Paulo, SP, Brasil.

Instituto Brasileiro de Avaliações e Perícias - IBAPE. (2012), "Norma de Inspeção Predial Nacional”. São Paulo, SP, Brasil.

Lei Estadual $\mathrm{n}^{\mathrm{o}} 6400 \quad$ (2013), $\quad$ Rio de Janeiro. http://alerjln1.alerj.rj.gov.br/CONTLEI.NSF/c8aa0900025feef6032564ec0060dfff/cda5d615434e ca4983257b260067692d. Acesso em 30 maio 2021.

Lessa, A. C. G. (2021), “Inspeção Predial Aplicada à Edifício Histórico - Estudo de Caso Capela de Leitão da Cunha no Município Trajano de Moraes, RJ'. Trabalho de Conclusão de Curso (Graduação em Engenharia Civil) - Universidade Federal Fluminense, Escola de Engenharia, Niterói, RJ, Brasil.

Prieto, A. J., Silva, A., Brito, J., Macías-Bernal, J. M., Alejandre, F. J. (2017). "The Influence of Pathological Situations on Churches Functionality: An Approach Based on Historical Records, International Journal of Architectural Heritage", 11:4, 566-587, DOI: 10.1080/15583058.2016.1272011.

Teixeira, B., Costa \& Silva, A. J. (2020). "Elaboração de Mapa de Danos de Prédio Histórico: um estudo de caso em fachadas com revestimento em pintura da Escola Politécnica da Universidade de Pernambuco”. Congresso Brasileiro de Patologia das Construções. Fortaleza, CE, Brasil.

Temp, A. L., De Moura Machado, B., Donelles Venquiaruto, S., Beatriz Scherer, C., Zoch de Carvalho, L. (2020). "Avaliação da degradação de fachadas de edificações do Patrimônio Histórico do Município de Alegrete - RS”. Congresso Brasileiro de Patologia das Construções. Fortaleza, CE, Brasil. 